\title{
A Blockchain Microsites-Based Ecosystem for Learning and Inclusion
}

\author{
Valéria Farinazzo Martinss, ${ }^{1,}$, Solomon Sunday Oyelere ${ }^{2}$, Lukasz Tomczyk ${ }^{3}$, \\ Gabriel Barros $^{4}$, Özgür Yaşar Akyar ${ }^{5}$, Maria Amelia Eliseo ${ }^{1}$, Cibelle Albuquerque \\ de La Higuera Amato ${ }^{6}$, Ismar Frango Silveira ${ }^{1,7}$ \\ ${ }^{1}$ Mackenzie Presbyterian University, Computing and Informatics Department, São \\ Paulo, Brazil \\ ${ }^{2}$ University of Eastern Finland, School of Computing, Joensuu, Finland \\ ${ }^{3}$ Pedagogical University of Cracow, Faculty of Social Science, Cracow, Poland \\ ${ }^{4}$ University of Azuay, LIDI, Cuenca, Ecuador \\ ${ }^{5}$ Hacettepe University, Physical Education and Sports Teaching, Ankara, Turkey \\ ${ }^{6}$ Mackenzie Presbyterian University, Post-graduation Program in Developmental \\ Disorders, São Paulo, Brasil
}

${ }^{7}$ Mackenzie Presbyterian University, Post-graduation Program in Electrical Engineering and Computing, São Paulo, Brasil

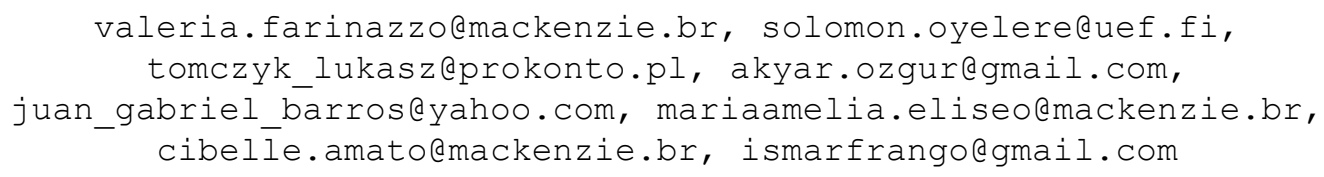

Abstract. Several initiatives have made available open educational resources, offered through educational platforms, aiming to achieve a broader audience, thus having the opportunity of democratizing knowledge. However, accessibility aspects in these resources still have many gaps. One is how to help teachers to prepare curricular contents available to all students, regardless of their limitations and disabilities. In this sense, this paper presents a digital ecosystem architecture, called SELI, that is being developed by a group of eleven European and Latin American countries. This ecosystem aims to provide an accessible learning environment and its contents, besides proper authoring tools based on recent technologies such as Blockchain, microsites, and universal accessibility guidelines.

\section{Introduction}

New solutions in Education are constantly addressed in scientific discussions and methodological publications. The concern for the quality of educational activities, also inclusion, is very often associated with the use of Information and Communication Technologies (ICT). With the development of the technical opportunities provided by digital media, a range of dilemmas emerge regarding two media pedagogy paradigms: opportunities and risk [Pyżalski et al. 2019]. New opportunities are identified with the latest Information Technology (IT) solutions. However, given the speed with which information is transferred, its diverse and modern forms to access content and multiple 
VIII Congresso Brasileiro de Informática na Educação (CBIE 2019)

Anais do XXX Simpósio Brasileiro de Informática na Educação (SBIE 2019)

ways to communicate via different devices (including smartphones), in many global educational contexts ICT has become the main didactic means. Employing ICT not only in the formal education system (schools) and outside of school (including adult education) is a constantly developing area, also thanks to the new services available in the information society [Ziemba 2017].

The intense development of technological solutions offered by digital media, including fast Internet connections and universal and easy-to-use data platforms translates into reception and implementation of these solutions in teaching and learning. New and highly useful ICT solutions implemented in other sectors, for example in banking, administration or IT, is in many cases reflected in the education industry. It is the representatives of the educational sector who often import modified ICT solutions in order to improve learning and teaching mechanisms. Transformation of the IT solutions into the education sector is required by modern education. On the other hand, it increases the attractiveness of classes, engagement and motivation among the students. However, teachers and education innovators see many barriers resulting from teachers' habits, poor technical infrastructure or widely understood cultural conditions which boundary factors are in using ICT in education [Stanković et al. 2018]. The material presented joins the debate over the use of modern IT solutions which have been successfully functioning in other sectors (mainly decentralized transfer of data and financial transactions). One of the many examples is blockchain which may, as shown by the initial analyses, support teachers (formal education) and trainers (digital inclusion), introduce the novelty effect and improve the quality of educational activities [Oyelere et al. 2019].

In order to contribute with the use of these up-to-date technologies in the educational context, aiming to improve the access and include people, this paper presents the Smart Ecosystem for Learning and Inclusion (SELI), a digital ecosystem architecture that aims to make available didactic material accessible also to people with disabilities and people that face other barriers to their proper access to educational resources. Part of this digital ecosystem provides an authoring tool for teachers (in the role of content authors) to prepare their material by following accessibility guidelines.

The paper is organized as follows: section 2 presents the details of the project being developed by eleven countries in European and Latin American contexts using the proposed architecture. Section 3 provides the theoretical background, and in section 4 the development architecture of the computational solution is detailed. Finally, section 5 presents some considerations and further steps for the project.

\section{The SELI project}

According to World Health Organization, in the world there are more than 1000 million people with some disability, congenital or acquired - they represent $15 \%$ of the world's population. It is estimated that one in each 20 people under 15 years old presents a moderate or severe disability. Different national patterns of disability are influenced by trends in health conditions and environmental and other factors, such as road traffic crashes, falls, violence or humanitarian emergencies including natural disasters and conflicts. These people face important barriers in accessing services, such as those for healthcare, education, employment, and social services, including housing and transport. Many issues have been responsible for the worldwide scenario of the lack of inclusion of these people with disabilities: inadequate legislation, policies and strategies; the lack of service provision; 
VIII Congresso Brasileiro de Informática na Educação (CBIE 2019)

Anais do XXX Simpósio Brasileiro de Informática na Educação (SBIE 2019)

negative attitudes and discrimination; lack of accessibility; inadequate funding; among others [Tomczyk, et al. 2019a].

Therefore, the project addresses the inclusion of different target groups such as the elderly, migrants, displaced youths, physically challenged, deaf and blind, through the proposal of a digital ecosystem that will allow the digital training of educators including higher education teachers, pre-service teachers, and trainers in the social service sectors to produce fully-inclusive content and courses.

According to Machekhina (2017), "Digitalization means transformation of all information types (texts, sounds, visuals, video and other data from various sources) into the digital language". We view educational digitalization as a process of developing new methodologies, learning environments, contents, and services relevant to the effectiveness of teachers, needs of the students (i.e. ultimately to secure a decent job), and meeting the challenges of modern-day learning ecosystems.

The concept "Smart" presents in this project means the use of intelligent technologies, such as Learning Analytics [Silva et al., 2017] and cloud computing-related technologies to support the digitization of the learning environment. Cloud computing and Blockchain enable ubiquitous access to shared resources over the Internet [Oyelere et al. 2019]. Learning Analytics in this project will focus on the collection, analysis and direction of learning data towards improving teaching and learning in the digital ecosystem. Such an ecosystem can be briefly described as a community network of interactions between organisms and their environment [Briscoe and De Wilde, 2006]. Similarly, a digital educational ecosystem provides a platform for stakeholders in the education sector such as educational institutions, students, parents, government, policy makers, technology providers and others to efficiently collaborate and interconnect to enable an individual to achieve learning objectives within an environment. In the context of SELI project (http://seliproject.org/), the educational ecosystem is extended to a broader concept since our target groups are often outside of the typical educational system - this includes the elderly, migrants, homeless, unemployed and other disadvantaged people. The benefits of the digitalization of education and training are the potential to push new pedagogy and methods in renewing the education sector, technology inclusion through open educational resources available across the regions, the development, and implementation of open learning environments to cater for both teacher's and student's digital needs, and improving the aptitude of teachers to adapt to new challenges.

In this context, an open access education and training platform is developed to harness the opportunity created by digital education. The platform encompasses the collaborative digital research, teaching, and learning framework, aimed at teaching the teachers and providing training for digital education. The teachers are meant to be coached on creating digital contents, working with digital contents, and supporting students' personalized learning paths (the elderly, unemployed, migrants, disabilities, homeless, or people living in remote or poorer areas). In addition, the digital educational platform investigates how the teachers use digital tools and services and the reaction of students within the framework. Learning analytics methods and tools were incorporated within the learning environment to collect and analyze data for decision making by the teachers and students.

The project is expected to improve learning results, address the competence needs of educators, renew teachers' methods by providing Learning Analytics results, and encourage lifelong learning for the benefit of disadvantaged groups in society. Innovative 
VIII Congresso Brasileiro de Informática na Educação (CBIE 2019)

Anais do XXX Simpósio Brasileiro de Informática na Educação (SBIE 2019)

technologies and methods such as Blockchain, global sharing pedagogy, open content, and educational data science will be adopted in the project to develop a state-of-the-art form of learning intervention.

The goal of the technical aspect of the project is to design a digital learning environment that leverages the project data, the seamless integration of pedagogy, and the activities required to make impact on learner achievement and retention. The optimal synergy for these three facets (data, pedagogy and action) has each notifying the other to build the optimal mix for every aspect of the digital learning environment. For example, the global sharing pedagogy, and digital storytelling pedagogy [Tomczyk et al. 2019b] will direct the type of actions to be taken by the teacher and learner. Both particular actions and pedagogies determine the kinds of data to be collected in this project. For example, learner-driven knowledge and skills creation (active learning, creative work), collaboration (working in peer groups, help-seeking and help-giving), networking (networking experience, cross-cultural learning), digital media competencies and literacy (the project as a digital tool, digital self-confidence). The degree of data collected will certainly impact the actions taken.

\section{Theoretical Background}

To facilitate the understanding of this paper, the following theoretical background is presented.

\subsection{Blockchain}

Blockchain is a transactional database based on a mutual distributed cryptographic ledger shared amongst all nodes participating in a system [Mainelli and Smith 2015]. It is considered among the main fields that will significantly affect people's lives upon Fourth Industrial Revolution [Chung and Kim 2016].

Although most of the solutions which are based on Blockchain are either prototypes or under development, it is clearly noticeable there is a growing interest in blockchain technology from academic communities. A brief literature review brings some works that attempted to discover potential of Blockchain technology as a new promising ICT-mediated solution in many contexts, as Education [Ocheja, Flanagan and Ogata 2018; Davies et al. 2015], Finance [Wu and Liang 2017], Health [Ito, Tago and Jin 2018], Commerce [Yuan et al. 2018], for instance. regarding the educational context, Oyelere et al. (2019) explore potential for authenticating and transmitting information such as graduation certificate, test report, learning achievements, performance metrics, academic profile or career interest through Blockchain.

Similarly, Williams (2019) points out the challenge for universities to manage erosion of their current near monopoly in awarding degrees and discusses implications for the academy of the convergence of Artificial Intelligence, Data Analytics and Blockchain technology. In addition, there are a growing number of universities which show efforts to make use of the opportunity that comes with Blockchain technology. For example, The University of Nicosia is the first school which uses Blockchain technology to manage students' certificates received from MOOC (Massive Open Online Courses) platforms [Sharples and Domingue 2016]. Also, MIT (Massachusetts Institute of Technology) and the Learning Machine Company are cooperating for online learning based on Blockchain technology [Chen at al. 2018]. This project implements three 
VIII Congresso Brasileiro de Informática na Educação (CBIE 2019)

Anais do XXX Simpósio Brasileiro de Informática na Educação (SBIE 2019)

fundamental components using Blockchain: course and user management; qualifications; and (partial) content management.

\subsection{Microsites}

One major challenge of content hosted inside Learning Management System (LMS) is interoperability. Content should be independent of the authoring tool and should execute in the same way in different architectures and should be able to display correctly in diverse devices. To address challenges like interoperability, reusability, portability, and durability, some standards and formats have been created. SCORM (Shareable Content Object Reference Model), for example, is a set of standards which incorporates these design criteria using web-based technologies [Robson, Barr and Aptos 2018] - another well-known standard addressing interoperability issues is LOM (Learning Object Metadata) [Barker 2005]. Compliance of these standards allows e-learning content to be interoperable, plug-and-play, browser-based, and allows instructional sequencing of selfpaced e-learning content.

In this context, a possibility for exchanging educational self-contained atomic objects is through a web technology called microsites. A microsite is considered a mini website (usually two to five pages) about a particular subject, keyword, or domain. It has less complexity than a full website and is used for localized content or for a single purpose. Although, microsites can include images, video, HTML, XML and Javascript files which are packed into a portable format like zip files. Microsites highlight a specific product or service. For example, when applied to education, it allows teachers to focus students' attention on a specific concept crucial to meet learning goals.

\subsection{Accessibility Guidelines}

For this work, the accessibility guidelines were divided into guidelines for accessible learning and guidelines for the presentation of Web content, as discussed below.

\section{A. Universal Design for Learning}

The concept of Universal Design for Learning (UDL) was born from the concept of Universal Design on the 80's years [Mace 1998], used in the educational context. It is a proposal that aims to guarantee access to content for all students, regardless of their limitations, so the educational goal has passed from the acquisition of knowledge to the student's experience.

In order to students to have access to knowledge, there must be some changes in four aspects of the curriculum: 1) Goals: listing the knowledge and skills necessary for students to reach; 2) Evaluation: monitoring the student's evolution and propose changes in the proposals whenever necessary; 3) Methods: offering several learning contexts, offering multiple types of learning resources and keeping the student motivated and proactive in the task; 4) Content: they should be in accordance with learning goals. According to the UDL principles, flexibility of curricula occurs through the ability to provide [CAST 2012]:

- Multiple modes of presentation: it can be reached by providing options for perception; offering options for language and symbols, and providing options for understanding.

- Action and expression: it is possible to present options for physical activity; for expression and communication, and for executive functions. 
VIII Congresso Brasileiro de Informática na Educação (CBIE 2019)

Anais do XXX Simpósio Brasileiro de Informática na Educação (SBIE 2019)

- Engagement: it can be improved by offering options to encourage interest; to sustain effort and persistence, and self-regulation learning.

In addition to the above, the use of technology is crucial to guarantee access to content, as well as to allow students to be more independent and autonomous in academic tasks. Technologies can reduce methodological barriers, providing the same curriculum for all, but with personalized goals, methods, evaluation and content [Alnahdi 2014].

\section{B. Web Accessibility Guidelines}

Concerns about accessibility in Web environments intensified in the '90s, when the "Web Content Accessibility Guidelines" (or WCAG 1.0) was developed and published. In order to make web content accessible to anyone, regardless of the device used, WCAG 1.0 defines 14 guidelines or general principles for an accessible project. Each guideline is associated with checkpoints that explain how it should be applied, providing links to technical documents with examples for the implementation of such points [W3C 1999]. Compliance with the recommendations of each priority level interferes with the compliance level achieved by the website [Isa et al. 2016]. Priority levels are numbered from 1 to 3 . Priority 1 (represented by A) is described as required requirements in the application, otherwise it will be impossible for one or more groups to access web content; priority 2 (represented by AA) is described as requirements that should have in the application, otherwise some groups will have difficulty accessing the content; and priority 3 (represented by AAA) are described as requirements that could be in the application, so that it is easier for some groups to gain access [W3C 1999].

In 2008, WCAG 2.0 was published with guidelines complementary to those of WCAG 1.0 and designed to be widely applied to Web technologies. These guidelines are divided into four main topics, which are: perceptible (information and interface components must be presented so that users can capture them); operable (interface and navigation components must be operable); understandable (information and use of the interface must be understandable); robust (content must be robust to be fully interpreted by a wide variety of users) [W3C 2008].

The recommendations of the model are separated into six sections: Marking, Behavior, Content / Information, Presentation / Design, Form and Multimedia. The content of the sections encompasses quality recommendations from developers for recommendations on accessibility features, creating video and audio alternatives for content and various forms of access such as keyboard and mouse [Isa et al. 2016].

\section{Ecosystem Architecture}

The digital ecosystem here proposed, following the definitions of Briscoe and De Wilde (2006), brings together a software platform and their users, following a set of preestablished but flexible roles. It also aggregates the artifacts produced through the platform and all formal and informal educational systems affected by its use. Figure 1 depicts the main elements of architecture of the project. The main elements present in the architecture are:

- Courses as microsites: each course, more than an aggregate of learning resources, is planned to be a self-contained entity ready to be made available through a microsite. These microsites could potentially connect to any management system 
VIII Congresso Brasileiro de Informática na Educação (CBIE 2019)

Anais do XXX Simpósio Brasileiro de Informática na Educação (SBIE 2019)

using well-known standards for content indexing and retrieval, like SCORM or LOM, or integrate to any grading system, attached or not to some learning standard.

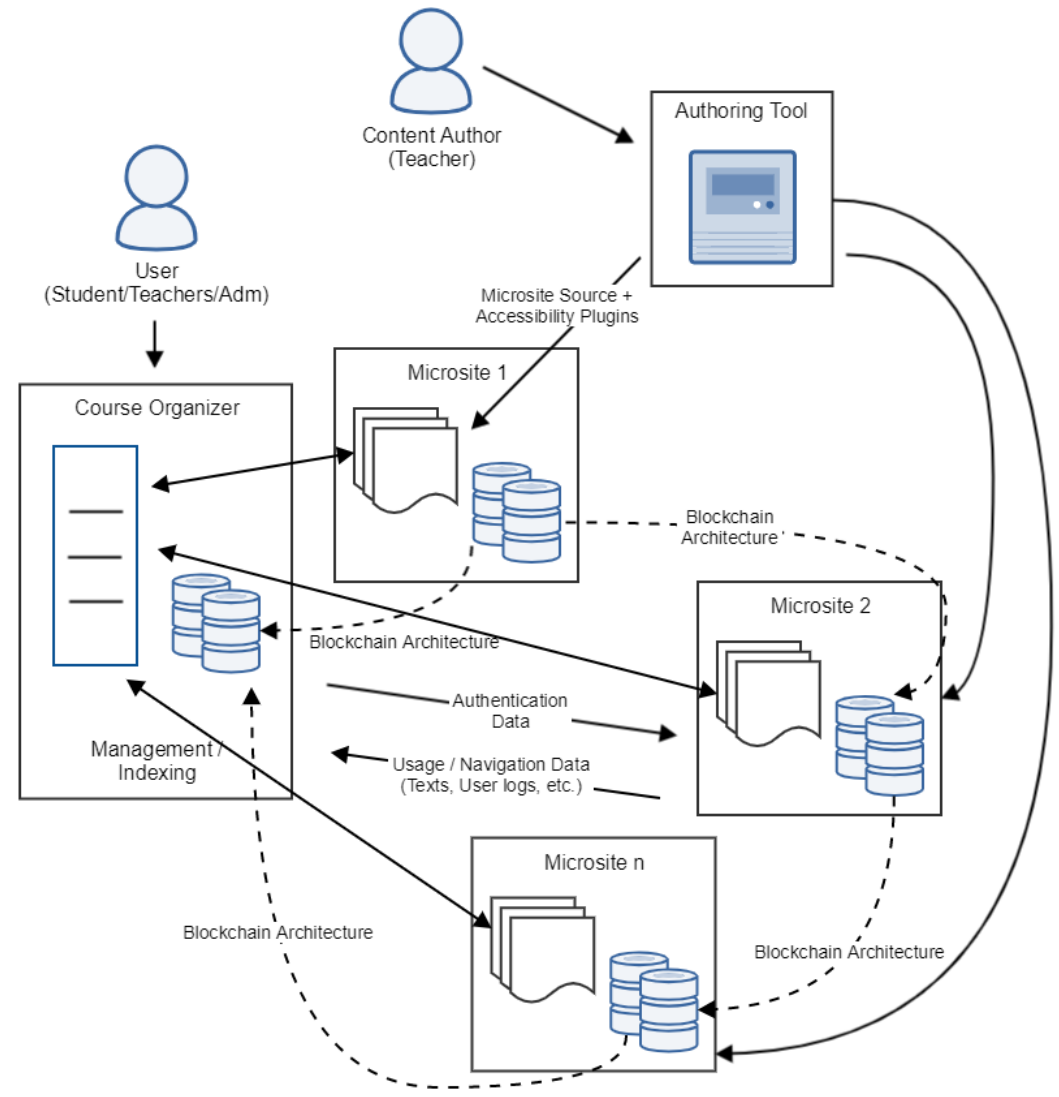

Figure 1. Architecture of the SELI project

- Blockchain-based infrastructure: by connecting all microsites in a blockchain structure, all transactional aspects are meant to be dealt in a distributed way, like authentication, course accreditation and students' micro-certification.

- Authoring tool: the project provides a semi-automated authoring tool for courses, giving support to accessibility checks and specific aiding plugins. In spite of not being an exclusive, indispensable tool for producing a microsite-based course for the ecosystem, the authoring tool guarantee the compatibility aspects, as well as helps course authors to identify accessibility leaks and to solve them.

- Course organizer: different from traditional LMS (Learning Management System), this tool is not supposed to be a course repository, but it relies on a lightweight proposal of being a course indexer. In this sense, it can be seen more as a LAMS (Learning Agents Management System), considering its user-centered approach. Course organizer is the responsible to put together all courses followed by some students, as well as the data generated by this usage (as logs and grades, for instance), and for that the connections between this piece of software and the microsites that deliver the courses must be provided and guaranteed by the ecosystem.

- Learner Analytics: a software component responsible for gathering all user data to provide both real-time feedback - using Learning Analytics techniques [Siemens, 2010] - and a posteriori analysis - by means of Educational Data Science techniques [Silva et al. 2017]. 
VIII Congresso Brasileiro de Informática na Educação (CBIE 2019)

Anais do XXX Simpósio Brasileiro de Informática na Educação (SBIE 2019)

\subsection{An Example of a Course Created by Authoring Tool}

As mentioned above, the authoring tool works semi-automatically, being able to provide accessibility features or validating resources provided by content authors (usually teachers). In the example of Figure $2 b$, it was selected that the original course (Figure 2a) was intended for people with low vision or blindness. Thus, the text contrast can be changed automatically. The tool also asks the author if a given resource was created in compliance with accessibility guidelines (subsection 3.3). For example, when the author makes available a figure, the tool asks for the audio description of this figure, as can be seen in Figure $2 \mathrm{~b}$. Each resource that the author makes available with the relevant accessibility characteristics is then marked as correct for that particular disability. If the author does not make the resource available with accessibility, the content is made available with an alert that is not accessible for that disability. The tool also provides a user guide to teach authors how to create their accessible content according to disability in a simple language.

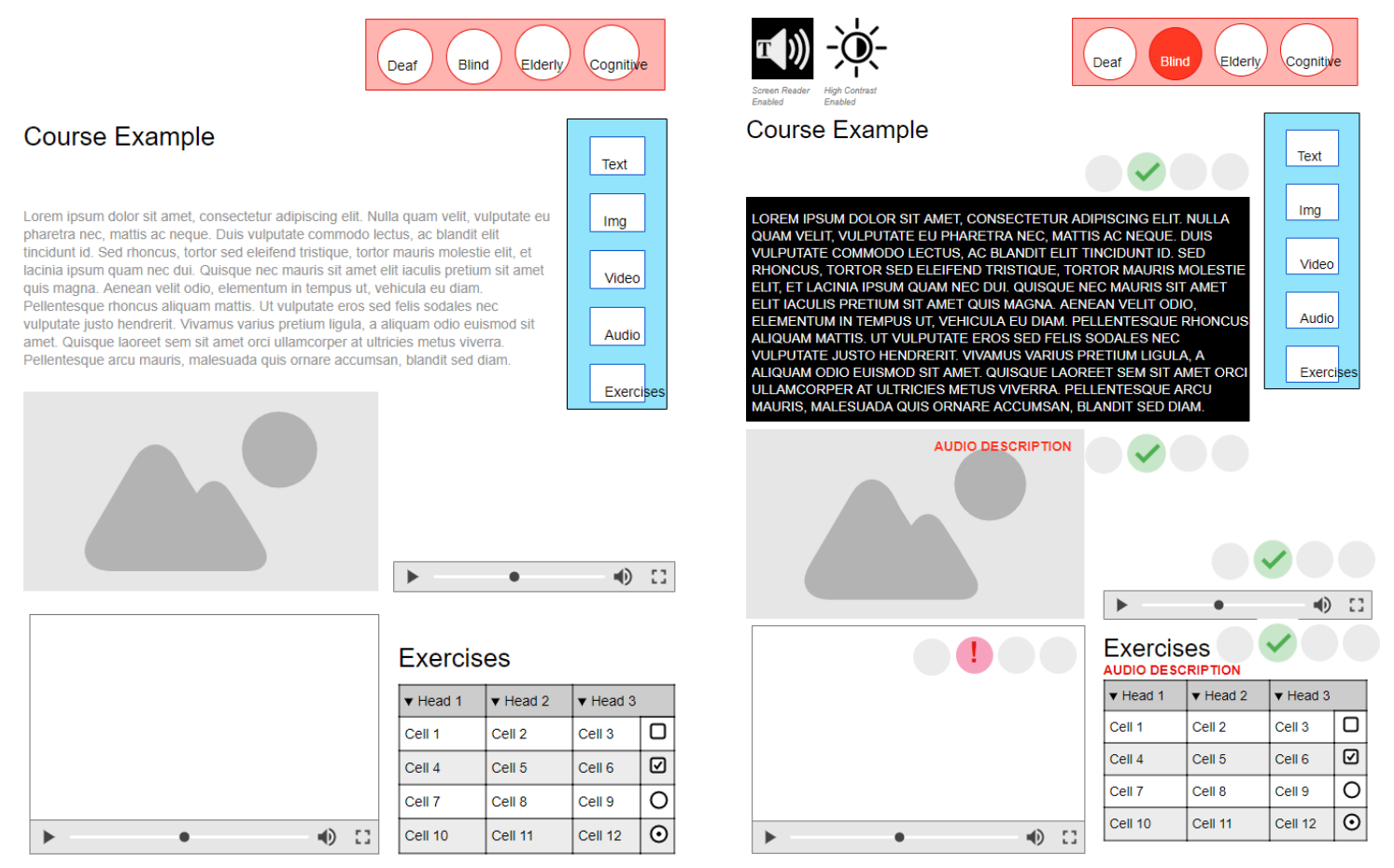

Figure 2. (a) A course without accessibility (b) A course with accessibility

\section{Final Considerations and Further Works}

This paper presented a blockchain microsites-based ecosystem for learning and inclusion that is being developed by a group of eleven countries from Europe and Latin America. This ecosystem aims to enable teachers to more easily create their didactic content and courses, which may include accessibility features. These contents will be available to students with or without disabilities through a web platform.

The ecosystem will be tested from the second semester of 2019 with teachers and students in the 11 countries that are part of the project, and from there, improvements will be made to the system. In addition, the teachers will test the authoring tool to prepare their material by inserting accessibility issues. Further work includes collecting users' opinions about the ecosystem and analyzing users'data. 
VIII Congresso Brasileiro de Informática na Educação (CBIE 2019)

Anais do XXX Simpósio Brasileiro de Informática na Educação (SBIE 2019)

\section{Acknowledgment}

This work was supported by the ERANET-LAC project which has received funding from the European Union's Seventh Framework Programme. Project Smart Ecosystem for Learning and Inclusion - ERANet17/ICT-0076SELI.

\section{References}

Alnahdi, G. (2014). Assistive Technology in Special Education and the Universal Design for Learning. The Turkish Online Journal of Educational Technology, 13, 18-23.

Barker, P. (2005). What is IEEE learning object metadata/IMS learning resource metadata. CETIS Standards Briefing Series, JISC (Joint Information Systems Committee of the Universities' Funding Councils).

Briscoe, G., \& De Wilde, P. (2006). Digital ecosystems: evolving service-oriented architectures. In Proceedings of the 1st international conference on Bio inspired models of network, information and computing systems, p. 17.

CAST. Universal Design Universal for Learning. Available in: http://www.cast.org. Accessed: July, 2019.

Chen, G., Xu, B., Lu, M., \& Chen, N.-S. (2018). Exploring blockchain technology and its potential applications for education. Smart Learning Environments, 5(1), 1.

Chung, M., \& Kim, J. (2016). The Internet Information and Technology Research Directions based on the Fourth Industrial Revolution. KSII Transactions on Internet \& Information Systems, 10(3).

Davies, R., Randall, D., \& West, R. E. (2015). Using open badges to certify practicing evaluators. American Journal of Evaluation, 36(2), 151-163.

Ito, K., Tago, K., \& Jin, Q. (2018). i-Blockchain: A Blockchain-Empowered IndividualCentric Framework for Privacy-Preserved Use of Personal Health Data. Proceedings of the $9^{\text {th }}$ International Conference on Information Technology in Medicine and Education (ITME).

Isa, W. A. R. W. M., Suhaimi, A. I. H., Ariffrn, N., Ishak, N. F., \& Ralim, N. M. (2016). Accessibility evaluation using Web Content Accessibility Guidelines (WCAG) 2.0. In 2016 4th International Conference on User Science and Engineering (i-USEr) (pp. 1-4). IEEE.

Mace, Ronald L. (1998). Universal design in housing. Assistive Technology 10.1: 21-28.

Machekhina, O.N. (2017). Digitalization of education as a trend of its modernization and reforming. Revista ESPACIOS. ISSN 07981015 Vol. 38, No 40.

Mainelli, M., \& Smith, M. (2015). Sharing ledgers for sharing economies: an exploration of mutual distributed ledgers (aka blockchain technology). Journal of Financial Perspectives, 3(3).

Ocheja, P., Flanagan, B., \& Ogata, H. (2018). Connecting decentralized learning records: a blockchain based learning analytics platform. Proceedings of the 8th international conference on learning analytics and knowledge.

Oyelere, S.S., Tomczyk, L., Bouali, N., Agbo, F. J. (2019). Blockchain technology and gamification - conditions and opportunities for education. In Jaroslav Veteška (ed.). Adult Education 2018 - Transformation in the Era of Digitization and Artificial 
VIII Congresso Brasileiro de Informática na Educação (CBIE 2019)

Anais do XXX Simpósio Brasileiro de Informática na Educação (SBIE 2019)

Intelligence. Česká andragogická společnost/Czech Andragogy Society Praha/Prague 2019 [ISBN 978-80-906894-4-2].

Pyżalski, J., Zdrodowska, A., Tomczyk, Ł. and Abramczuk, K. (2019). Polskie badania EU KIDS ONLINE. Najważniejsze wyniki i wnioski. Wydaw. Uniwersytet Adama Mickiewicza, Poznań.

Robson, R., Barr, A., \& Aptos, C. A. (2018). The new wave of training technology standards. In presented at the Interservice/lndustry Training, Simulation, and Education Conf.(I/ITSEC'18).

Sharples, M., \& Domingue, J. (2016). The blockchain and kudos: A distributed system for educational record, reputation and reward. Paper presented at the European Conference on Technology Enhanced Learning.

Siemens, G. (2010). What are learning analytics. Retrieved March, 10, 2011.

Silva, L. A., Silveira, I. F., Silva, L., Rodrigues, R. and Ramos, J. L. C. (2017) Ciência de Dados Educacionais: definições e convergências entre as áreas de pesquisa. In: Anais dos Workshops do Congresso Brasileiro de Informática na Educação -. p. 764-773.

Stanković, Z., Maksimović, J., and Osmanović, J. (2018). Cognitive theories and paradigmatic research posts in the function of multimedia teaching and learning. International Journal of Cognitive Research in Science, Engineering and Education (IJCRSEE), pages 107-114, v.6 n.2

Tomczyk L., et al. (2019a). Digital Divide in Latin America and Europe: Main characteristics in selected countries. Iberian Conference on Information Systems and Technologies (CISTI' 2019), IEEE.

Tomczyk, L., Oyelere, S.S., Puentes, A., Sanchez-Castillo, G., Muñoz, D., Simsek, B., Akyar, O.Y., Demirhan, G. (2019b). Flipped learning, digital storytelling as the new solutions in adult education and school pedagogy. In Jaroslav Veteška (ed.). Adult Education 2018 - Transformation in the Era of Digitization and Artificial Intelligence. Česká andragogická společnost/Czech Andragogy Society Praha/Prague 2019 [ISBN 978-80-906894-4-2].

W3C. (1999). Web Content Accessibility Guidelines 1.0. Disponível em: https://www.w3.org/TR/WAI-WEBCONTENT/. Accessed: July, 2019.

W3C. (2008). Web Content Accessibility Guidelines 2.0. Available in: $<$ https://www.w3.org/Translations/WCAG20-pt-PT/> . Accessed: July, 2019.

Williams, P. (2019). Does competency-based education with blockchain signal a new mission for universities? Journal of Higher Education Policy and Management, 41(1), 104-117.

Wu, T., \& Liang, X. (2017). Exploration and practice of inter-bank application based on blockchain. Paper presented at the 2017 12th International Conference on Computer Science and Education (ICCSE).

Yuan, P., Xiong, X., Lei, L., \& Zheng, K. (2018). Design and Implementation on Hyperledger-Based Emission Trading System. IEEE Access, 7, 6109-6116.

Ziemba, E. (2017). The Contribution of ICT Adoption to the Sustainable Information Society. Journal of Computer Information Systems, pages 116-126, v. 59 n. 2. 